\title{
The Health Differences and Influencing Factors of Elderly in Urban and Rural Areas: Based on Data of CLHLS 2014
}

\author{
Mengling $\mathrm{He}^{*}$, Jian Zhou \\ School of Public of Management, Jinan University, Guangzhou, China \\ Email: ^hemengling1@163.com
}

How to cite this paper: He, M. L., \& Zhou, J. (2018). The Health Differences and Influencing Factors of Elderly in Urban and Rural Areas: Based on Data of CLHLS 2014. Advances in Applied Sociology, 8, 295-305. https://doi.org/10.4236/aasoci.2018.84016

Received: March 8, 2018

Accepted: April 13, 2018

Published: April 16, 2018

Copyright $\odot 2018$ by authors and Scientific Research Publishing Inc. This work is licensed under the Creative Commons Attribution International License (CC BY 4.0).

http://creativecommons.org/licenses/by/4.0/

\begin{abstract}
The health of the elderly has always been an important issue to China in recent years. Based on the 6729 samples of 2014 Chinese Longitudinal Healthy Longevity Survey (CLHLS), this paper focuses on the health differences among the elderly in urban and rural China. The results show that: the health status of urban and rural elderly in China has significant differences. The elderly in rural areas are healthier than urban. The health of the elderly is affected by many factors. Education, marriage, health insurance, quality of sleep, participation in social activities and exercise have a positive effect on the health of the elderly. Positive and optimistic older people are in better health. The health status of the elderly with children's financial support is superior to that of the elderly without financial support. The health effects of caring for the elderly are the opposite of financial support.
\end{abstract}

\section{Keywords}

Urban and Rural Areas, Elderly, Health Differences, Influencing Factors

\section{Introduction}

The aging population is a problem that most countries in the world are facing. China attaches great importance to the health problems of the elderly. On October 18, 2017, Chairman Xi Jinping pointed out at the 19th CPC National Congress that we should implement the strategy for a healthy China and respond proactively to the aging population. For a long time, China has implemented the dual urban-rural structure. Although China continues to implement the reform of the household registration system and narrows the gap between urban and 
rural areas, overall the level of economic development in China's urban and rural areas and the level of social security systems are still quite different. For example, the urban economy is more prosperous and urban residents have higher incomes. Urban residents have better health services and facilities than rural residents. Therefore, this article focuses on analyzing the differences and influencing factors of the health status of urban and rural residents.

The meaning of health is relatively broad. In 1978, the World Health Organization (WHO) reaffirmed that health is a state of complete physical, mental and social wellbeing (The, 2004). Scholars' measurements of the health status of the elderly are diverse, covering subjective and objective aspects, including physical health, mental health, quality of life and so on. In 1963, Katz proposed the use of Activities of daily living (ADL) to measure the health status of the elderly, which was adopted by many scholars (Katz, Ford, Moskowitz, Jackson, \& Jaffe, 1963). ADL mainly objectively evaluates the six self-care capacities of the elderly to reflect their physical health status. This article will follow Katz's ADL as a reflection of the health status of older adults.

There are many influencing factors of the health status of the elderly, and people from different angles to analyze. From the existing research, the influencing factors can be roughly summarized into five categories: individual characteristics, socioeconomic status, lifestyle, sick situation (such as the prevalence of chronic diseases, type of illness, hospitalization) and others. Most researchers believe that generally men have healthier body than women in elderly (Lin, $\mathrm{Xu}$, Ke, \& Liu, 2017; Weng, 2017; Xu \& Yu, 2016). However, studies have also shown that there is no obvious gender difference in elderly self-reported health (Jang, Wei, \& Zhang, 2015). As the age increases, the physical function of the elderly gradually decays, and the health status declines (Feng, \& Zhou, 2017). But Li \& Li (2014) believes that this is just the age of physical health aspects of performance, not significant in terms of mental health, and older people aged 90 and above have better self-rated health than those aged 60 - 69 (Li \& Li, 2014). Most scholars think that marriage promotes health and the health status of spouses with older adults is better than that of divorced or widowed elderly people ( $\mathrm{Lu}$, Wang, Jin, Gu, \& Shi, 2015). Major events such as divorce and widowhood have a significant impact on the mental health of the elderly, which can cause serious physical and psychological trauma to the elderly (Ren \& Wang, 2017). But some scholars also found that marriage has a negative impact on the health of the elderly, indicating that the elderly in non-married status are healthier than the elderly in marriage ( $\mathrm{Hu} \& \mathrm{Li}, 2011)$. Hu \& Nan (2016) used the national survey data concluded that there are significant differences in the health of the elderly between urban and rural areas: the urban elderly have a higher risk of illness and have more illnesses than the rural elders (Hu \& Nan, 2016). However, Lu et al. (2015) used the data from the elderly in western Ningxia to come to an inconsistent conclusion: the elderly in western Ningxia have no obvious difference between urban and rural areas in self-reported health (Lu, Wang, Jin, Gu, \& Shi, 
2015). Many Chinese Studies have shown that socioeconomic status has a positive impact on the health of the elderly, the stronger the economic capacity of the elderly, the better their health status (Xu, 2015; Lu \& Guo, 2017). Better economic conditions and high academic qualifications have significant positive effects on self-evaluation health and mental health (Xue \& Ge, 2017). In terms of lifestyle, good habits can keep a healthy body (Zhang, Yan, \& Li, 2006). Exercise, participate in social activities have a great improvement on health (Li \& Zhou, 2017; Ruan, Wang, Wang, Lei, \& Wei, 2016). A healthy lifestyle can reduce the cumulative disadvantages of socioeconomic conditions for the health of the elderly, and long-term physical exercise can improve the health of the elderly (Wang, 2017). Some researchers also pay attention to the social activity's influence on elderly. Older people who have never participated in community cultural activities are more likely to feel unhealthy (Yan \& Wu, 2015).

Through combing the existing literature, we find that there are many factors affecting the health of the elderly, but there are still some differences in the specific impact of each factor. Besides, some of their conclusions are contradictory. This article will use the newly public national survey data CLHLS 2014. Mainly from China's special urban-rural dual system national conditions, in-depth study of the impact of urban and rural elderly health differences and influencing factors.

\section{Data Sources and Description Analysis}

\subsection{Data Sources}

The data used in this article is " 2014 Chinese Longitudinal Healthy Longevity Survey" (CLHLS) ${ }^{1}$. This data is a follow-up survey conducted by Peking University Center for Healthy Aging and Development Study. The CLHLS survey covers 23 provinces in China. In 2014, it surveyed 7192 elderly people. The object of this study is the elderly 65 years and older. In the analysis of the model, the final contains a dozen variables. By excluding some missing values and unsuitable cases, the final sample size for inclusion in the statistical model study was 6729 . The average age of elderly is 85.58. In 6729 respondents, there are 3645 females, accounting for $54.17 \%, 45.83 \%$ are males. More than half are rural people (53.84\%).

\subsection{Description Analysis}

The purpose of this study is to explore whether there is any difference in the health of urban and rural residents. If so, what factors are affected? We assume that there are differences in the health of the elderly between urban and rural areas in China. Use ADL as a proxy for the health of the elderly. The questionnaire was measured by six indicators of ADL. Whose answer is that all six of ${ }^{1}$ Peking University Center for Healthy Aging and Development Study, 2017, "Chinese Longitudinal Healthy Longevity Survey (CLHLS) (1998-2014)”, http://dx.doi.org/10.18170/DVN/UWS2LR, Peking University Open Research Data Platform, V1 [UNF:6:mwXPPX2r8SnXlvyT9BTDlw==]. 
ADL's "without assistance", we think he or she is "healthy" and " $\mathrm{Y}=1$ "; if there's a "with assistance", he or she is "unhealthy" and " $\mathrm{Y}=0$ ", forming a dichotomous ADL variable. As we can see from the Table 1, there are 1655 elderly are "unhealthy", accounting for $24.74 \% .75 .26 \%$ of the elderly are "healthy". Nearly a quarter of elderly ADLs are restricted. This shows that most elderly in China have a good activity of daily life.

We combine "city" and "town" into one variable, while retaining "rural". The proportion of elderly people in urban and rural areas was $46.16 \%$ and $53.84 \%$. The average age of respondents was 85.58 years old.

In order to better analyze the impact of various factors on the health of the elderly in urban and rural areas, six groups of variables were screened by stepwise regression. They are personal characteristics $\left(\mathrm{X}_{1}\right)$, socioeconomic conditions $\left(\mathrm{X}_{2}\right)$, lifestyle $\left(\mathrm{X}_{3}\right)$, chronic and physical examination $\left(\mathrm{X}_{4}\right)$, mental health $\left(\mathrm{X}_{5}\right)$ and family support $\left(\mathrm{X}_{6}\right)$. Personal characteristics include age and gender. Socioeconomic conditions cover the elderly's marital status, level of education, living standard, whether they have access to community services and social insurance. Lifestyles include sleep time and quality, smoking and drinking or not, do regular exercise and participation in organized social activities or not. In addition, chronic diseases, physical examination and other variables were added. Table 2 shows the distribution of the specific variables.

Table 1. The percentage of elderly people's health.

\begin{tabular}{ccc}
\hline $\mathrm{Y}(\mathrm{ADL})$ & Frequency & Percentage \\
\hline 0 & 1665 & 24.74 \\
1 & 5064 & 75.26 \\
\hline
\end{tabular}

a. $\mathrm{N}=6729$.

Table 2. Description of the basic situation of the elderly (\%).

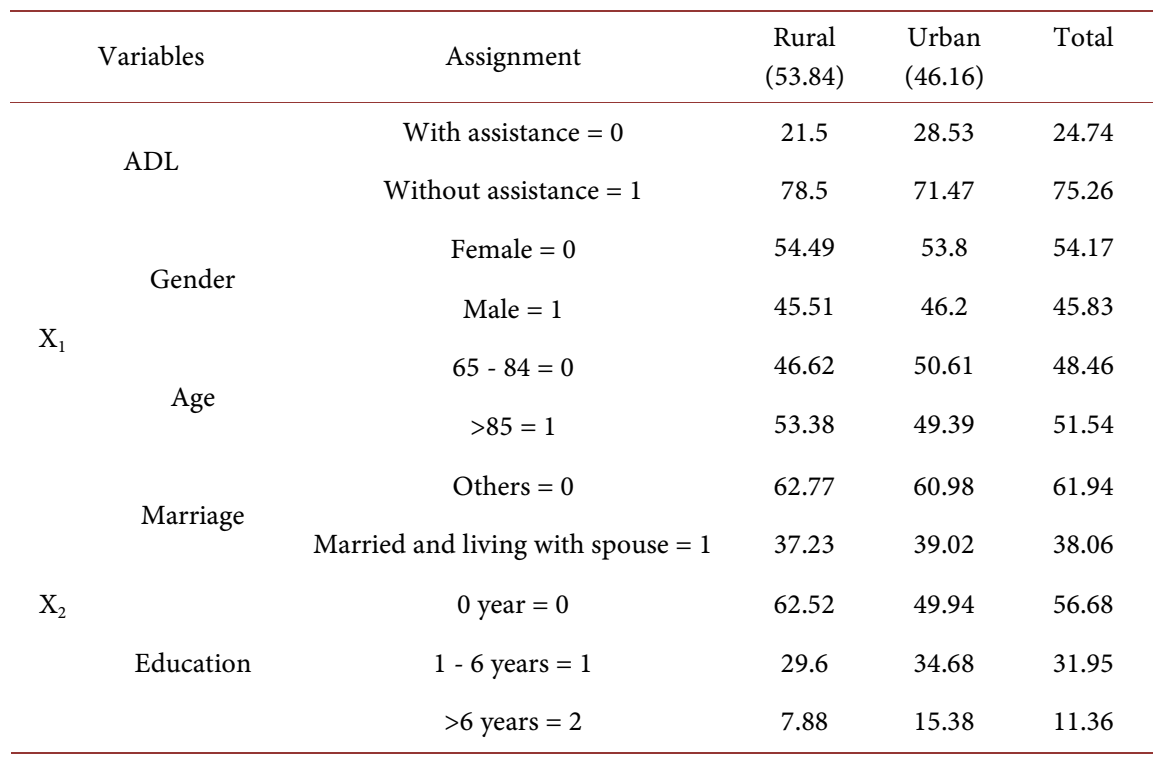




\section{Continued}

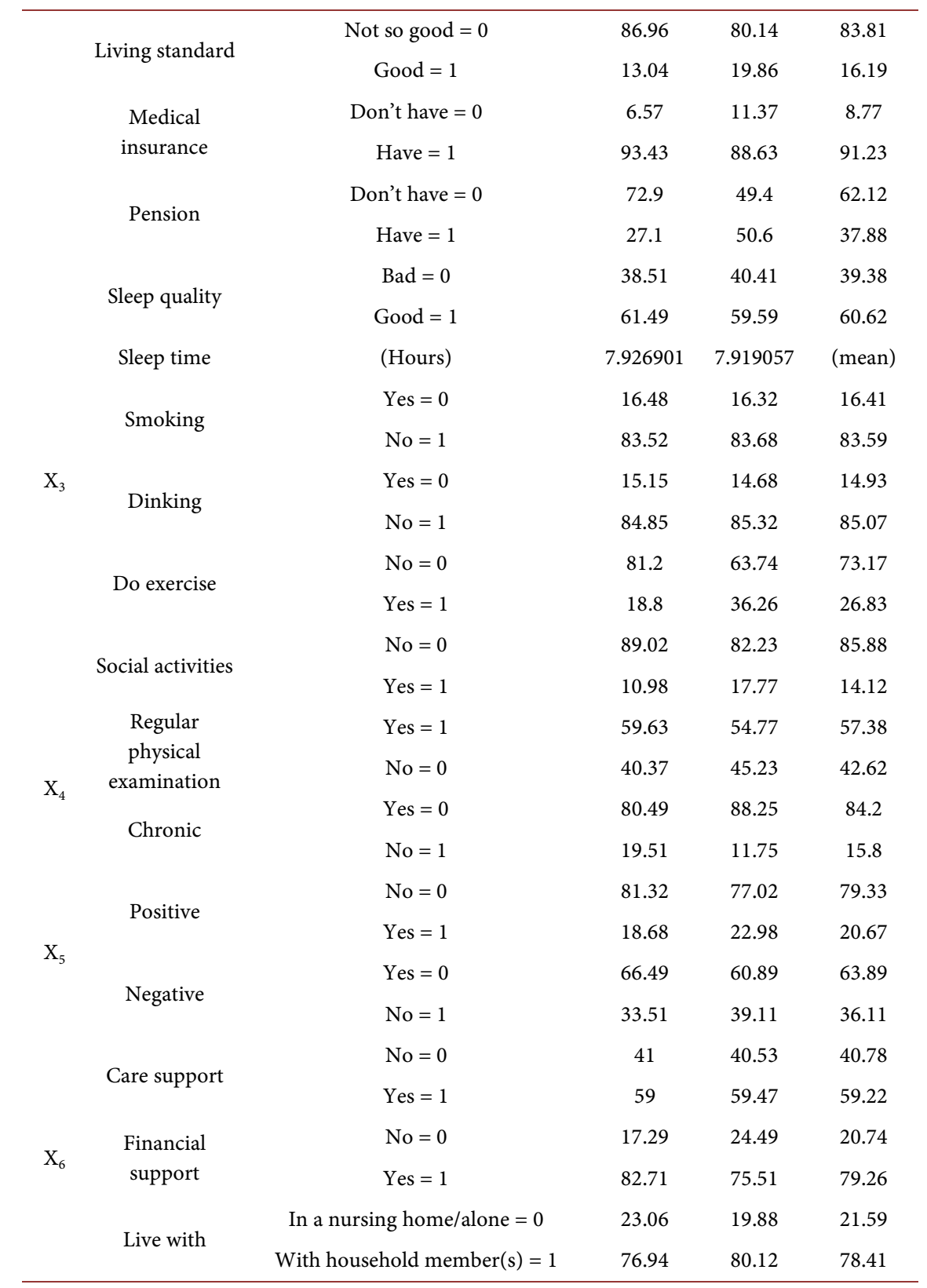

a. $\mathrm{N}=6729$.

\section{Method}

Since the dependent variable "health" is binary variable in this article: "health = 1 " and "unhealthy $=0$ ". The dichotomous Logistic statistical model was used in this article. Since the focus of this article is to explore the health differences between urban and rural seniors, we first use resident (rural or urban) as an independent variable, and ADL as a dependent variable to analyze the overall differences in health among elders. Then establish multiple nested models, add control variables $\mathrm{X}_{1}-\mathrm{X}_{6}$ in turn to analyze the differences in health between urban and rural elderly. 


\section{Empirical Result}

In the regression model, we define $\mathrm{ADL}=$ " 0 " as "with assistance". $\mathrm{ADL}=$ " 1 " as "without assistance". Therefore, in the regression results, if the regression coefficient is less than 0 , then the health condition of the elderly is more likely to be bad, while the regression coefficient is greater than 0 , then the health status of the elderly is better.

Model 1 in Table 3 considers only the effects of urban-rural factors on the health of the elderly. As can be seen from the results in the table, the difference between the health of the elderly in urban and rural areas is very significant $(P<$ $0.01)$. Taking rural areas as reference group, the coefficient of urban area is -0.376 , which shows that urban elderly has poorer health status than that of rural elderly people.

Table 3. Logistic regression models for factors influencing the health of urban and rural elderly.

\begin{tabular}{|c|c|c|c|c|c|c|c|c|}
\hline & Variables & Model 1 & Model 2 & Model 3 & Model 4 & Model 5 & Model 6 & Model 7 \\
\hline \multirow{8}{*}{$\mathrm{X}_{1}$} & \multirow{2}{*}{ Residence } & $-0.376^{\star * *}$ & $-0.493^{\star * *}$ & $-0.381^{\star * *}$ & $-0.486^{* * *}$ & $-0.420^{* * *}$ & $-0.420^{\star * \star}$ & $-0.494^{\star * *}$ \\
\hline & & -0.0567 & -0.0602 & -0.0698 & -0.0736 & -0.0825 & -0.0835 & -0.107 \\
\hline & \multirow{2}{*}{ Gender } & & $0.371^{\star * *}$ & $0.213^{\star * *}$ & 0.023 & 0.0016 & -0.0146 & $-0.247^{\star}$ \\
\hline & & & -0.0615 & -0.0792 & -0.0871 & -0.0971 & -0.0983 & -0.127 \\
\hline & \multirow{2}{*}{ Age } & & $-1.570^{\star * \star}$ & $-1.432^{\star * *}$ & $-1.268^{* * *}$ & $-1.220^{* * *}$ & $-1.169^{* * *}$ & $-0.895^{\star * *}$ \\
\hline & & & -0.0668 & -0.0811 & -0.0846 & -0.0935 & -0.0946 & -0.12 \\
\hline & \multirow{2}{*}{ Marriage } & & & $0.321^{* * *}$ & $0.230^{* * *}$ & $0.237^{\star *}$ & $0.235^{\star *}$ & $0.282^{\star \star}$ \\
\hline & & & & -0.0855 & -0.0891 & -0.099 & -0.1 & -0.134 \\
\hline \multirow{8}{*}{$\mathrm{X}_{2}$} & \multirow{2}{*}{ Education } & & & $0.184^{* * *}$ & 0.0844 & 0.0898 & 0.094 & $0.189^{* *}$ \\
\hline & & & & -0.0617 & -0.066 & -0.0726 & -0.0736 & -0.0916 \\
\hline & Living & & & 0.12 & -0.0173 & -0.0691 & -0.117 & $-0.343^{\star *}$ \\
\hline & standard & & & -0.0932 & -0.0981 & -0.109 & -0.111 & -0.143 \\
\hline & \multirow{2}{*}{$\begin{array}{c}\text { Community } \\
\text { service }\end{array}$} & & & 0.061 & -0.00753 & 0.103 & 0.0987 & 0.0845 \\
\hline & & & & -0.069 & -0.0724 & -0.0824 & -0.0836 & -0.109 \\
\hline & \multirow{2}{*}{$\begin{array}{c}\text { Medical } \\
\text { insurance }\end{array}$} & & & $0.515^{* * *}$ & $0.499^{* * *}$ & $0.429^{* * *}$ & $0.421^{* * *}$ & $0.282^{*}$ \\
\hline & & & & -0.106 & -0.112 & -0.122 & -0.124 & -0.16 \\
\hline \multirow{10}{*}{$\mathrm{X}_{3}$} & \multirow{2}{*}{ Pension } & & & $-0.294^{* * *}$ & $-0.364^{\star * *}$ & $-0.324^{* * *}$ & $-0.321^{\star * *}$ & $-0.281^{\star *}$ \\
\hline & & & & -0.0726 & -0.0762 & -0.0842 & -0.0852 & -0.111 \\
\hline & \multirow{2}{*}{ Sleep quality } & & & & $0.304^{* * *}$ & $0.342^{\star * *}$ & $0.311^{\star * *}$ & $0.262^{\star \star}$ \\
\hline & & & & & -0.0781 & -0.0878 & -0.0891 & -0.109 \\
\hline & \multirow{2}{*}{ Sleep time } & & & & $-0.0804^{* * *}$ & $-0.0981^{\star \star \star}$ & $-0.0891^{\star \star \star \star}$ & $-0.0372^{\star *}$ \\
\hline & & & & & -0.0146 & -0.0169 & -0.017 & -0.0159 \\
\hline & \multirow{2}{*}{ Smoking } & & & & $-0.530^{* * *}$ & $-0.498^{\star * *}$ & $-0.507^{\star * *}$ & $-0.480^{* * *}$ \\
\hline & & & & & -0.119 & -0.133 & -0.134 & -0.17 \\
\hline & \multirow{2}{*}{ Dinking } & & & & $-0.377^{* * *}$ & $-0.402^{* * *}$ & $-0.392^{* * *}$ & $-0.396^{\star *}$ \\
\hline & & & & & -0.12 & -0.134 & -0.135 & -0.173 \\
\hline
\end{tabular}




\section{Continued}

\begin{tabular}{|c|c|c|c|c|c|c|c|c|}
\hline & & & & & $0.919^{* * *}$ & $0.942^{\star * *}$ & $0.891^{\star * *}$ & $0.970^{* * *}$ \\
\hline & Do exercise & & & & -0.0986 & -0.107 & -0.108 & -0.133 \\
\hline & Social & & & & $0.777^{\star * *}$ & $0.783^{\star * *}$ & $0.742^{* * *}$ & $0.824^{\star * *}$ \\
\hline & activities & & & & -0.145 & -0.156 & -0.157 & -0.183 \\
\hline & Regular & & & & & $0.368^{* * *}$ & $0.346^{* * *}$ & $0.296^{* * *}$ \\
\hline $\mathrm{x}$ & $\begin{array}{c}\text { physical } \\
\text { examination }\end{array}$ & & & & & -0.0806 & -0.0815 & -0.105 \\
\hline & Chronic & & & & & $0.513^{* * *}$ & $0.517^{* * *}$ & $0.764^{* * *}$ \\
\hline & (II) & & & & & -0.117 & -0.119 & -0.151 \\
\hline & Pesitive & & & & & & $0.633^{* * *}$ & $0.508^{\star * *}$ \\
\hline & tositre & & & & & & -0.116 & -0.144 \\
\hline$\Lambda_{5}$ & N & & & & & & $-0.295^{* * *}$ & $-0.357^{* * *}$ \\
\hline & 1vegative & & & & & & -0.0831 & -0.105 \\
\hline & & & & & & & & $-2.098^{\star * *}$ \\
\hline & tale suppont & & & & & & & -0.129 \\
\hline $\mathrm{x}$ & Financial & & & & & & & $0.554^{\star * \star}$ \\
\hline$\Lambda_{6}$ & support & & & & & & & -0.127 \\
\hline & Jive w & & & & & & & -0.136 \\
\hline & Live & & & & & & & -0.131 \\
\hline & $f_{2}-$ & $1.295^{* * *}$ & $2.161^{\star * *}$ & $1.469^{* * *}$ & $2.640^{* * *}$ & $2.335^{\star * *}$ & $2.303^{* * *}$ & $2.684^{* * *}$ \\
\hline & & -0.0404 & -0.0711 & -0.139 & -0.233 & -0.263 & -0.267 & -0.358 \\
\hline
\end{tabular}

Standard errors in parentheses: ${ }^{* *} P<0.01,{ }^{*} P<0.05,{ }^{*} P<0.1$. a. N=6729.

Model 2 is based on the model 1, but also included personal characteristics $\left(\mathrm{X}_{1}\right)$ : gender, age factor variables. Coefficient of urban elderly is -0.493 ; it is still very significant $(P<0.01)$. This shows that after controlling for gender and age, the health differences between urban and rural elderly has not changed. There are also differences in the health of older persons of different genders, with a coefficient of 0.371 for older men, indicating that men are healthier than women. Age is negatively related to the health of the elderly. Older persons over 85 years old have poorer health status than $65-84$, which is consistent with previous studies that the older the elderly is, the worse of physical condition is.

Model 3 added variables of socioeconomic status $\left(\mathrm{X}_{2}\right)$. The coefficient of urban elderly is -0.381 and remained significant. In a series of factors of socioeconomic conditions, marital status, education level, availability of medical insurance and pension are significant. It is better for the elderly to live with their spouses than to be unmarried (including widowed or divorced). Older people who are educated are healthier than those who are uneducated. This means education has a positive effect on the health of the elderly. But the living standards have no significant effect on the health of the elderly. This is contrary to the conclusion of most people that think rich people have a better health. The influence of pension and medical insurance on the health of the elderly is significant. As we can see from model 3, their influence is the opposite. The elderly 
who has medical insurance is healthier than the one who hasn't. However, the one who has a pension has a worse health than the one who don't have. This may be attributed to the better access to medical services for the elderly with Medicare. In China, the reimbursement rate of medical insurance reached 50\% $90 \%$. Some people who don't have medical insurance may not be able to afford medical expenses and give up treatment, so they have a bad health. Most elderly people in China who have pension are workers when they were young. Prolonged labor hurt them a lot, so these people may have a worse body condition. Community service is not significant for the health of the elderly.

In model 4 , we add $\mathrm{X}_{3}$. The regression coefficient of has changed when the elderly lifestyle has been added. In this model, gender difference is not obvious. We can find that six variables of lifestyle all are significant. People usually think of that one has a healthy way of life (such as regular participation in exercise, participate in various activities), the healthier body he'll has. This is in line with our expectations. Sleep quality and sleep time showed the opposite result. Elderly have a better quality of sleep is healthier than those who don't. But it is not means the more hours you sleep, the healthier body you have. In this model's result, it's opposite. The longer the elderly sleep, the worse their physical condition. That may because elderly people have a bad health will spend more time in bed. Elderly doing exercise or attend activities have a better health condition than others. Obviously, the result of this regression is consistent with most people. But when we look at the result of smoking $\&$ dinking, it is strange! Those who smoke and drink alcohol are healthier than those who do not. If we consider Li \& Li (2014)'s point of view, it is well understood. He said that, this result may be due to the existence of selectivity, which means, those who have had an adverse effect on their health by smoking and drinking do not smoke or drink alcohol any more. Or they have long since passed away. And the remaining elderly who continue to smoke and drink are the better-off seniors ( $\mathrm{Li} \& \mathrm{Li}, 2014$ ).

Based on the model 4, model 5 on the increase of chronic diseases and whether have an annual routine physical examination or not, the CLHLS questionnaire, which covers 24 common chronic diseases. It is defined as " 0 " for the elderly with chronic diseases and " 1 " for the elderly without chronic diseases. In this model, the elderly with no chronic disease are better than the one with one or more chronic diseases, as expected. Elderly people who have regular physical exams once a year are in better health. The coefficient of urban elderly is -0.42 and remained significant. Compare with model 5 , the absolute value is smaller, but compared with model 1 , it is larger. That means, the real differences of health between rural and urban are larger than we estimated.

Model 6 adds the psychological status of the elderly as a control variable. The difference between urban and rural areas is still significant at this time, but the regression coefficient has not changed, indicating that the psychological condition is not the main reason for affecting the health differences between urban and rural residents. Older people who have a positive psychological assessment are healthier than those who are negatively evaluated. 
The final model 7, adds family supports as control variables. Family support here are simple defined as care support, financial support and living with family. The result of the regression shows that the influence of caring support and economic support is the opposite. Older people who have caring support are in worse health, while older people with financial support are in better health. It is also easy to understand that the disabled elderly need more family care while the healthy elderly need less. Whether living with family members has little difference in the health effects of the elderly.

Overall, there are significant differences in the health status of the elderly in urban and rural areas. From model 1 to model 7, the regression coefficients for urban elderly were both negative and $P<0.01$. This shows that the health status of the rural elderly is significantly better than that of the urban elderly. From model 2 to model 7, although there are irregular changes in the regression coefficients, their absolute values are larger than that of model 1, indicating that the actual differences between urban and rural residents are greater than the regression results. The impact of age on the health of the elderly is negative. The health impact of marriage on the elderly is positive. Community service has no significant effect on the health of urban and rural elderly. Medical insurance is a factor that affects the difference in the health of the elderly in urban and rural areas, but its regression coefficient gradually decreases from 0.515 to 0.282 , indicating that its actual impact is smaller. Children's financial support and care support can ease the health differences brought about by medical insurance. Pension and sleep time have a negative effect on the elderly's health. Sleep quality, exercise and attend social activity have a positive effect on the elderly's health. The ability of the elderly to perform daily activities is affected by whether they suffer from chronic diseases. Elderly people with chronic diseases have poor daily activities. However, elderly people who regularly have physical examinations are in better physical condition, because physical examination can better understand your physical condition, timely prevention and treatment of diseases. The more optimistic the elderly are, the better they are. The health status of the elderly with children's financial support is superior to that of the elderly without financial support. The health effects of caring for the elderly are the opposite of financial support.

\section{Conclusion}

There are significant differences in the health status of elderly people in urban and rural areas. Older people in rural areas are in better health than urban. Age, marriage, social insurance, lifestyle, psychological status and family support are all factors. Marriage, positive attitude, physical exercise, and participation in social activities have a positive impact on the health of the elderly. We should pay attention to the physical and mental health of the elderly. We should encourage the elderly in urban and rural areas to face the growth of their age with a positive and optimistic attitude. At the same time, the government should pay attention to the chronic conditions of the elderly and provide better prevention and 
treatment services.

\section{Funding}

This work is supported by the 2016 " 13 th five-year plan" fund of the Guangzhou Philosophy and Social Sciences (2016GZYB20).

\section{References}

Feng, Y. R., \& Zhou, L. Z. (2017). Influences of Living Habits and Family Supports on the Health Conditions of Empty Nest Elderly in Urban and Rural Areas. Chinese Journal of Gerontology, 37, 3591-3594.

Hu, H. W., \& Li, Y. J. (2011). Study on the Health Status of Senior Citizens in China and Its Influencing Factors-Based on the Ordered Probit Model. Journal of Shanxi University of Finance and Economics, 33, 1-8.

Hu, S. Y., \& Nan, S. X. (2016). Health Differences between Urban and Rural Elderly-Analysis Based on the National Baseline Data of CHARLS in 2011. Scientific Research on Aging, 4, 74-80.

Jang, X. Q., Wei, M., \& Zhang, W. J. (2015). Study on the Health Status and Influencing Factors of China's Aging Population. Population Research, 37, 46-56.

Katz, S., Ford, A. B., Moskowitz, R. W., Jackson, B. A., \& Jaffe, M. W. (1963). Studies of Illness in the Aged. Journal of the American Medical Association, 185, 914-919. https://doi.org/10.1001/jama.1963.03060120024016

Li, A. H., \& Zhou, H. X. (2017). Effects of Lifestyle Intervention on Cognitive Function of the Elderly. Scientific Research on Aging, 5, 46-58.

Li, J. X., \& Li, C. H. (2014). Health Difference of the Elderly between the Rural and Urban Districts. Population Journal, 36, 37-47.

Lin, Z., Xu, X. L., Ke, P., \& Liu, B. (2017). Role of Gender in the Correlation between the Elderly's Cognitive Function and Social Tie and Social Support. Modern Preventive Medicine, 44, 2211-2214.

Lu, H. Y., Wang, X. L., Jin, X., Gu, B. R., \& Shi, Q. (2015). Comparison of the Elderly Health Self-Assessment between Urban and Rural Area in the West of Ningxia. Modern Preventive Medicine, 42, 2767-2769.

Lu, J. H., \& Guo, R. (2017). An Empirical Study on Health and Health Inequality of Chinese Elderly: Based on Regional and Community Perspective. Population Journal, 39, 57-67.

Ren, B. L., \& Wang, J. M. (2017). Social Support and Mental Health of the Elderly. Chinese Journal of Gerontology, 37, 1530-1533.

Ruan, H. Q., Wang, B. X., Wang, Q. L., Lei, J. B., \& Wei, Y. X. (2016). Socioeconomic Status, Lifestyle and Health Status among Older Adult-A Empirical Research Based on Data from Beijing. Scientific Research on Aging, 4, 68-79.

The, E. (2004). Declaration of Alma-Ata International Conference on Primary Health Care, Alma-Ata, Ussr, 6-12 September 1978. Development, 47, 159-161. https://doi.org/10.1057/palgrave.development.1100047

Wang, F. B. H. (2017). Social Cause or Healthy Option? An Empirical Study on the Health Inequality of Elderly in China. China Sport Science and Technology, No. 6, 13-20.

Weng, X. X. (2017). Explaining the Puzzle of Gender Difference of Functional Limitation Incidence of Chinese Elderly. Population Research, 41, 76-86. 
$\mathrm{Xu}$, J. (2015). Gender Difference of the Elderly Health in China and Its Decomposition. Journal of Northwest Normal University (Social Science), No. 1, 139-144.

$\mathrm{Xu}, \mathrm{L}$., \& Yu, L (2016). The Influence of Social and Economic Status on Elderly Heath: Empirical Analysis Based on CGSS 2013 Data. Statistics \& Information Forum, 31, 52-59.

Xue, X. D., \& Ge, K. X. (2017). The Effect of Socioeconomic Status on the Health of the Elderly in China: Evidence from the Chinese Longitudinal Healthy Longevity Survey. Population \& Development, 23, 61-69.

Yan, J., \& Wu, J. (2015). Discussing the Relationship between the Elders' Health and Community Participation Based on Survey in Four Cities. Chinese Health Service Management, 32, 495-498.

Zhang, A. L., Yan, A. M., \& Li, B. X. (2006). Investigation Report on the Relationship between Senior Citizens' Life Habits and Health. Modern Preventive Medicine, 33, 979-980. 